\title{
Behavioral Problems in the Classroom and Underlying Language Difficulties
}

\author{
Jodi Tommerdahl \& Peggy Semingson \\ Department of Curriculum \& Instruction, University of Texas at Arlington, Arlington, TX 76015, USA \\ Correspondence: Jodi Tommerdahl, Department of Curriculum and Instruction, Center for Mind, Brain and \\ Education, University of Texas at Arlington, Arlington, TX 76015, USA. Tel: 1-817-272-1242. E-mail: \\ joditom@uta.edu
}

Received: June 28, 2013 Accepted: July 16, 2013 Online Published: July 29, 2013

doi:10.11114/jets.v1i2.163

URL: http://dx.doi.org/10.11114/jets.v1i2.163

\begin{abstract}
Dealing with the behavioral problems of students is one of many dimensions of most educators' and schools' requirements. While research has repeatedly shown that a large number of children with behavior problems have underlying, unrecognized language difficulties, few schools have implemented programs where children with problem behavior are evaluated in terms of these skills. This paper provides information to teachers about (1) the links between behavior and language, (2) the levels at which language can be impaired including phonology, grammar and pragmatics, (3) how language impairment can be recognized and (4) what can be done in the classroom to support the language skills of this group. Special attention is paid to the pragmatic level of language as impairment at this level may be misdiagnosed as behavior problems. The information provided is targeted towards pre-K and elementary school age, but can also be adapted for older children.
\end{abstract}

Keywords: behavior, language, language impairment, pragmatics, education, classroom management

\section{Introduction}

The movie "The Miracle Worker" (Coe \& Penn, 1962) provides a vivid depiction of the way that language impairment can impact behavior. Helen Keller, who had little to no expressive language, experienced frustration and significant behavior challenges in her struggle to communicate with others. However, her behavior showed marked improvement after she learned her first sign, the hand symbol and meaning of the word "water", from her teacher Anne Sullivan.

Dealing with students who present difficult behavior is a challenge nearly every classroom teacher has encountered. Teachers have been taught to observe students, document behavioral issues, and try to identify the possible causes of behavior. Teachers take many different approaches to dealing with inappropriate behaviors and also in trying to identify the source of such behaviors.

One often overlooked but critical area associated with behavioral problems is a difficulty in a child's ability to either comprehend or produce language. (Ripley \& Yuill, 2005). Difficulties in these areas are known as 'language impairments'. More specifically, language impairment is a difficulty in one or more of the many areas of processing needed to learn and use the rules of language. These difficulties could exist at the level of combining sounds (phonology), of implementing grammatical rules or using language appropriately according to context (pragmatics). A review of 26 studies carried out by Benner, Nelson, \& Epstein (2002), showed that 71\% of children with emotional and behavioral disorders were also found to have underlying language impairment. Speech and language pathologists or intervention specialists who are working in a pull-out or inclusion program may want to work collaboratively with classroom teachers to assist in determining if language impairment may be connected with specific behaviors in order to provide simple and effective classroom-based interventions.

This article describes how behavioral problems can mask language difficulties and provides specific examples of informal diagnostic tools that can be used in classrooms to begin to document and monitor possible language issues. Components of language are briefly defined and examples of informal data collection are provided for each component of language. Ideas for assessment and interventions for both large and small groups are provided that suit the first and second levels of the three-tiered response to intervention model that classroom teachers can 
administer. In the three-tiered model, the first level consists of the classroom teacher playing a role in providing quality instruction that is derived from research-based practices (Vaughn, Linan-Thompson, \& Hickman, 2003), screening children's ability and providing in-class group support. Activities suggested here can also be used in the second tier for children who do not respond adequately to tier one intervention. This tier focuses on more targeted work for a smaller group. The final tier, consisting of individual intervention following full evaluation, is best handled by a team made of members including the classroom teacher as well as a speech and language pathologist.

Ideally, screening for language impairment should be carried out at as young an age possible. Unfortunately, language impairment often goes unnoticed, meaning that teachers at any grade level should be aware of its symptoms. For this reason, all of the screening procedures and activities, except where otherwise reported, are applicable for all school age children. Each activity can be slightly adapted to keep the interest of children of different ages.

\section{Nature and Significance of Language Impairment}

Language impairment includes problems in the production and/or comprehension of language. For example, a child with a difficulty at the grammatical level may find it confusing to distinguish between the present and past tense. This would lead to problems not only in producing appropriate sentences, but also in understanding both oral and written language. This does not include problems with speech production such as lisps or other pronunciation problems but instead focuses on our unconscious knowledge of linguistic rules. When language impairment exists in a person having normal or above average IQ and is not due to any known reasons such as neurological disease, that person may be said to have "specific language impairment" (Leonard, 1998).

Although the connection between unrecognized language impairment and poor behavior has been well established in the research literature, language impairment is still not being well recognized in the population of children with behavioral problems. Several research studies have shown that both children and adults with behavioral problems often have underlying language difficulties which were undiagnosed. Bryan, Freer and Furlong (2007) examined 58 juvenile offenders aged from 15-17, and found that $90 \%$ of them had below average language skills with $46-67 \%$ of them scoring in the poor or very poor group. A study by Hagaman, Trout, DeSalvo, Gehringer and Epstein (2010) focused on 80 children who were in a residential educational setting for reasons of social, emotional and behavioral problems (mean age 15.7). None had been identified with language impairment in the past, but language testing showed that $54 \%$ of the children had signs of language impairment. Furthermore, despite having normal IQs, these students performed well below their peers academically, which is a common problem in children with language impairment (Conti-Ramsden, Durkin, Simkin, \& Knox, 2009; Snowling, Adams, Bishop, \& Stothard, 2001).

A smaller but similar study was carried out by Fontenot, Hayes and Frilot (2011) with 11 children ranging in age from 13 to 16 who were attending an alternate education program for students suspended / expelled due to behavior problems. Again, none had been identified as having language impairment and all were administered clinical language testing. In this case, all 11 of the children were shown to have language impairment.

There are several reasons that language impairment is highly prevalent in settings where the common denominator is poor behavior. First, impaired language is difficult to recognize by most teachers and parents who lack information about potential language problems. Second, weakness in language comprehension ability is particularly damaging to a child's social relationships, and their ability to understand instructions and perform academically, leading to understandable frustration. Finally, as these children seem linguistically typical and are not recognized as having any developmental disabilities, parents, teachers and peers tend to place these children into a category of "weak" or "stupid", despite the fact that they may well have normal intelligence.

Perhaps at particular risk is a group known as having "Pragmatic Language Impairment" (PLI) (Bishop, Chan, Adams, Hartley, \& Weir, 2000). Language impairment can strike different children at different levels of language. Some may have problems at the phonological level, or the broader awareness of sound and sound combinations, while others may have difficulties at the grammatical or semantic level or a combination of any of these. However, the pragmatic level of language is the most social, directly related to context, and including the areas of figurative language and politeness. Some researchers suggest that the symptoms of language impairment are being incorrectly diagnosed as a social, emotional or behavioral problem (Redmond, 2002). We can take the example of children who lack pragmatic skills and therefore understand only the literal meaning of sentences as opposed to the more nuanced, figurative meaning. When children like these are asked a question such as "Can you open your book to page 43?", it is possible that they will process only the literal meaning and appropriately respond with the logical answer of "yes" while not understanding the more subtle message of the statement which implies that they should actually open their book. It is clear to see how this kind of weakness in pragmatic 
processing could be seen as uncooperativeness by teachers and fellow students.

In order to determine whether the incidence of Pragmatic Language Impairment and poor behavior were highly correlated, a study by Ketelaars, Cuperus, Jansonius, and Verhoeven (2010) examined the prevalence of each in a community sample of 1,364 4-year old children. Using the Children's Communication Checklist (CCC-2) (Bishop, 2003) and the Strengths and Difficulties Questionnaire (Goodman, 1997), the researchers found high overlap between the two groups of diagnoses, with the most common type of behavioral problems for children with PLI being hyperactivity and a lack of pro-social behavior.

Given what we know regarding the high incidence of undiagnosed language impairment that exists in children with behavioral difficulties, our attention now changes to how classroom teachers can recognize the possible existence of impaired language.

\section{Recognizing Language Impairment in Children}

A child's language problems are most likely to be recognized by parents and teachers. Parents have the advantage of having information such as whether their children started speaking later than other children or whether anyone else in the family has been diagnosed with a language problem. Classroom teachers, on the other hand, are able to compare a child of a given age with several other children of a similar age. Teachers also see children in both social and learning contexts that parents perhaps don't.

The signs of language impairment that teachers are often told to look for might include children not following the 'rules' of conversation and resisting participation in group activities. However, this type of general advice may not be specific enough for use in a behavioral setting as these symptoms may well apply to a typical child with behavior problems. For that reason, the following tasks specifically focus on linguistic activities that may suggest the presence of language impairment. Although we typically think of language as being a cohesive entity, the field of linguistics breaks language down into components which can be analyzed individually despite their interdependence. The following activities focus on the language components of phonology, grammar and pragmatics and can be adapted to a range of age groups.

\subsection{Phonological Component}

Phonological awareness is the broader awareness of sounds. It is an auditory skill and shouldn't be confused with the visual introduction of print and the alphabet. It includes the abilities to rhyme, detect syllables of individual words, and ultimately, blend, segment, and manipulate phonemes, the smallest individual units of sound in spoken words. The more discrete and sophisticated skill of phonemic awareness is a smaller subset of phonological awareness and includes the ability to hear and manipulate the sounds in words at the phoneme level. Deficits in phonological awareness have been linked to reading disability and to diagnosis with dyslexia and other reading challenges (Blachman, 1989).

There are simple ways to assess a student's skills in phonological awareness. Typically, these are measured on common early childhood screening and progress monitoring tools such as the DIBELS (Dynamic Indicators of Early Basic Literacy Skills) (Good \& Kaminski, 2002), however, older students who aren't normally assessed on such tasks can be given simple tasks to determine possible risk factors in this language area. Simple ways for classroom teachers or intervention specialists to assess phonological awareness are provided below. Teachers should demonstrate the task prior to asking the student to do it. Note that the following tasks in Table 1 are not inclusive of all the component parts of phonological and phonemic awareness.

Table 1. Informal Tasks that Assess Phonological and Phonemic Awareness

\begin{tabular}{ll}
\hline Language Area & Task \\
\hline $\begin{array}{l}\text { Phonological awareness: } \\
\text { Rhyming }\end{array}$ & $\begin{array}{l}\text { Provide three words orally, two of which rhyme. Ask the student which of the words } \\
\text { doesn't rhyme. }\end{array}$ \\
$\begin{array}{l}\text { Phonological awareness: } \\
\text { Syllabication }\end{array}$ & $\begin{array}{l}\text { Ask the student to clap out or tap out the number of syllables in his or her name or other } \\
\text { common use words. }\end{array}$ \\
$\begin{array}{l}\text { Phonemic awareness: } \\
\text { Segmenting }\end{array}$ & $\begin{array}{l}\text { Say a word with two phonemes and a short vowel sound such as "it" or "up". Ask the } \\
\text { student to count the number of sound he or she hears in the word. Do an example to } \\
\text { model first. Work up to a word with three phonemes such as "cup", "man", or "tin". }\end{array}$ \\
Phonemic awareness: & $\begin{array}{l}\text { Say a word with two or three phonemes to the student, stretching out the word slowly. Ask } \\
\text { the student to "say it fast". Do an example to model first. Work up to a word with three } \\
\text { plending }\end{array}$ \\
\end{tabular}


For everyday instruction, we also recommend the teacher-friendly text Phonemic Awareness in Young Children (1993) by Adams, Foorman, Lundberg and Beeler. The benefit of this teacher-friendly text is that it is research-based and provides clear examples for teachers who may or may not have extensive training in this area. The text also scaffolds instruction sequentially and systematically through sequenced lessons ranging from the most basic skills of phonological awareness (e.g., sentence segmentation and rhyming tasks) to the most complex tasks of phonemic awareness (e.g., asking students to manipulate individual units of sound).

\subsection{Grammatical Component}

Another area of language where children can have difficulty is at the level of grammar. Grammar can be thought of as the part of linguistic knowledge that lets us make meaningful sentences through various word orders. Grammar allows us to distinguish between phrases such as "the dog bit the man" and "the man bit the dog". Two main ways of looking at children's grammatical ability will be presented; measuring mean length of utterance (MLU) and looking at specific grammatical aspects of spoken language. For both, the teacher would begin by gathering a language sample of approximately 100 utterances or more for each child. This would involve recording the child's language for later transcription and would ideally be done in a conversational context. A transcript might look something like this:

Teacher: Can you tell me about a movie you've seen lately?

Child: I don't remember.

Teacher: I think you mentioned one about astronauts the other day.

Child: Yeah, you're right.

Child: It was really good!

Teacher: So what happened in the movie?

Child: It was some people who went into space but they got lost.

\subsubsection{MLUw}

MLU measures the average length of an utterance and is a measure of grammatical complexity and therefore of a child's linguistic ability. Typically, this measure has been carried out through counting the exact number of morphemes (MLUm), or the smallest meaningful parts of language, within each utterance. However, Rice et al. (2010) have shown that simply calculating the number of words in the average utterance (MLUw) can show a difference between children with and without language impairment. In order to calculate MLUw, the number of words in each utterance produced by the child needs to be counted. The example above is made up of four utterances.
I don't remember.
(4) $\mathrm{I}+\left(\mathrm{do}+\mathrm{n}^{\prime} \mathrm{t}\right)+$ remember
Yeah, you're right.
(4) yeah $+($ you + 're $)+$ right
It was really good
It was some guy chasing cats in space.

After counting the words, they are added together and divided by the number of utterances. In this case, there were 20 words and 4 utterances leading to an MLUw of 5. Although a sample this short would not be reliable for calculating MLUw, it illustrates how the process is carried out. It is important to use only intelligible utterances.

Once the teacher has determined what the child's MLUw is from a given sample, the information may be used in different ways. If carrying out this exercise on an entire class, teachers can compare the MLUs of different students to each other, looking for outliers, or they could compare them with the list of average MLUs for children both with and without language impairment published by Rice et al. (2010) for children from age 3 to 9 . MLUs can also be used throughout a school year to measure progress in language development with the use of repeated samples.

\subsubsection{Specific Grammatical Items}

Another way to use language samples is to look at each child's use of specific grammatical forms that have been shown to be problematic for many children with impaired language. Rice and Wexler (1996) demonstrated that language impaired children often have difficulty with the use of the regular past tense, the third person singular (which distinguishes between the verb forms of 'I walk' versus 'she walks'), and the verbs 'be' and 'do' whether in their auxiliary or lexical forms. If analysis of a child's language sample shows errors being made in regard to these parts of grammar when their peers have mastered them, this is a red flag for language impairment. It is 
important to note that children who are learning English as an additional language will often make grammatical errors as part of the typical learning process (Maratsos, 2000). These errors are not to be confused with language impairment. The same holds true for speakers of a dialect whose grammatical usage may be different from others in the classroom.

Table 2. Potential Markers of Language Impairment

\begin{tabular}{ll}
\hline Tense & Examples \\
\hline regular past tense & walked, jumped \\
third person singular & he eats, she watches \\
be (is, are, was, were) & I am coming, I am happy \\
do (did) & I didn't go, she did it \\
\hline
\end{tabular}

Classroom teachers can also devise language tasks which elicit these forms in order to more quickly evaluate a child's performance. For example, the teacher could take a turn saying "I'm going to walk to the grocery store" where it is the student's role to then say "I walked to the grocery store". Similar activities could be devised for each grammatical form described above.

\subsection{Pragmatic Component}

As stated earlier, the pragmatic component is extremely important to evaluate, given the similarity of appearance between pragmatic problems and behavioral difficulties. Fortunately, several pragmatic checklists for teachers, most of them free, can be found online. One example of this is the Checklist for Pragmatic Language Challenges (Cohen \& Diamond, n.d.). For those schools who have the financial resources, less than $\$ 200$ will buy them the CCC-2 discussed above (Bishop, 2003) which is often considered to be the 'gold standard'.

\subsection{Combined Levels}

One final suggested activity is to ask children to retell a favorite story, movie or tv show. Pay close attention to the child's ability to reconstruct a logical sequence of events that explain the story. This can also be an opportunity to listen for grammatical forms such as correct verb tenses, but most importantly the teacher can look at the child's overall mastery over language manipulation. Does the child have a name for all the required characters, events and objects or is there much use of terms like "this guy" or "a thing"? This could point to a problem with vocabulary or mental access to the lexicon.

\section{Following up}

After carrying out informal assessment activities on students, teachers may possibly have questions about the language ability of one or more of the students. If this is the case, it is important that these questions be answered and not left to guesswork. In addition to the assessment tools described here, teachers will need to monitor the students' everyday abilities to communicate in the classroom and these should be documented in a confidential notebook, forming anecdotal records for later use, if a referral for intervention has not yet been made. This collected data can be confidentially shared with the appropriate members of the referral team at the school and at various points in monitoring students' academic progress. For instance, data can be collected when students are in the process of being monitored and intervention strategies are being put in place by the classroom teacher as tier 1 tracking. This type of data can also suggest formal diagnostic testing by appropriate personnel.

As further follow-up, teachers can include additional language support in the curriculum. Depending on the type of language difficulty exhibited by the students, teachers can work with an interdisciplinary team to support students in their academic and behavioral needs. Furthermore, an official diagnosis of language impairment for a child should lead to immediate targeted and individualized language support which will hopefully improve the child's language, communication skills and ensuing behavior. Such interventions can be implemented by not only the classroom teacher and parents, but also by any intervention specialists such as speech and language pathologists, psychologists, counselors and specialist teachers who might be working with the student.

For instance, the following classroom activities are associated with gains in language development:

1). Small-group phonological and/or phonemic awareness instruction using the structured program by Adams and colleagues in Phonemic Awareness in Young Children (1998) or a similar teaching program.

2). Explicit teaching, teacher modeling, and guided practice of the grammatical forms that the child finds problematic, such as the past tense. This instruction should provide both direct instruction (DI), as needed, as 
well as more holistic opportunities for students to participate in authentic language use. If the student is currently receiving speech and language services, work with the speech and language pathologist to come up with activities that best address student needs.

3). Classroom discussion about the pragmatics, or social, use of language. Pragmatic meaning is the least visible in language, as pragmatic information is not explicitly present in the literal meaning of sentences. Model and demonstrate examples of how language changes in formal versus informal contexts, how sarcasm is expressed through tone and how stress on certain words in a sentence can give the sentence different meanings. Discuss idiomatic expressions and puns and the idea that words can't always be taken in a literal sense. Reading children's books like Peggy Parish's Amelia Bedelia (1963) can help students with this type of literal and pragmatic language use.

\section{Discussion}

In closing, a high degree of correlation exists between behavioral and language problems. Signs of both can be similar or easily coexist because language impairment is difficult to recognize. It is therefore useful for teachers who work with children with behavior problems to be knowledgeable regarding signs of language impairment. The information presented in this article can help teachers and specialists to informally probe different areas of children's language to better inform them of whether language impairment may be present. In turn, this information can help get children the help they need.

Addressing language problems in the classroom, ideally from a young age, is what could be called a 'win/win/win/win' situation. Providing language support to children who needs it first improves the child's language and improved language comprehension strongly boosts the child's ability to learn. Furthermore, improved ability in spoken language strengthens children's social relationships. Added benefits include reduction in frustration leading to better behavior with perhaps the ultimate 'win' being better educational outcomes.

Despite the fact that most teachers, especially those of young children who are learning to read and write, are highly trained in the structure of language, few receive specific training around language impairment. Increased awareness of this problem and its link with behavior is one of the many tools in teachers' arsenals to help recognize and treat problems early, avoiding ensuing problems with behavior and learning.

\section{References}

Adams, M. J., Foorman, B. R., Lundberg, I., \& Beeler, T. (1998).Phonemic awareness in young children: A classroom curriculum. Baltimore, MD: Paul H. Brookes.

Benner, G. J., Nelson, J. R., \& Epstein, M. H. (2002). Language skills of children with EBD: A literature review. Journal of Emotional and Behavioral Disorders, 10, 43-56. http://dx.doi.org/10.1177/106342660201000105

Bishop, D. (2003) The Children's Communication Checklist-2.2. London, England: The Psychological Corporation.

Bishop, D., Chan, J., Adams, C., Hartley, J. \& Weir, F. (2000). Conversational responsiveness in specific language impairment: Evidence of disproportionate pragmatic difficulties in a subset of children. Development and Psychopathology, 12, 177-199. http://dx.doi.org/10.1191/0265659005ct290oa

Blachman, B. A. (1989). Phonological awareness and word recognition: Assessment and intervention. In A. G. Kamhi \& H. W. Catts (Eds.), Reading disabilities. A developmental perspective (pp. 133-158). Boston, MA: College Hill.

Bryan, K., Freer, J., \& Furlong, C. (2007). Language and communication difficulties in juvenile offenders. International Journal of Language \& Communication Disorders, 42, 505-520. http://dx.doi.org/10.1080/13682820601053977

Coe, F., \& Penn, A. (1962). The miracle worker. United States: Metro-Goldwyn-Mayer Studios Inc. http://dx.doi.org/10.1080/13682820601053977

Cohen, P. L., \& Diamond, S. (n.d.) Let's talk: What you should know about speech and language development in the classroom. Retrieved from http://caeyc.org/main/caeyc/proposals/pdfs/LetsTalk3.pdf

Conti-Ramsden, G., Durkin, K., Simkin, Z., \& Knox, E. (2009). Specific language impairment and school outcomes. I: Identifying and explaining variability at the end of compulsory education. International Journal of Language \& Communication Disorders, 44, 15-35. http://dx.doi.org/10.1080/13682820801921601

Fontenot, J. L., Hayes, S. L., \& Frilot, C. (2011). Language deficits and behavior problems in children placed in alternate education settings. Contemporary Issues in Communication Sciences and Disorders, 38, 36-40. 
http://www.nsslha.org/uploadedFiles/NSSLHA/publications/cicsd/2011S-Language-Deficits-Behavior-Prob lems.pdf

Good, R. H., \& Kaminsky, R. A. (Eds.). (2002). Dynamic indicators of early basic literacy skills (6 ${ }^{\text {th }}$ ed.). Eugene, OR: Institute for the Development of Educational Achievement.

Goodman, R. (1997). The strengths and difficulties questionnaire: a research note. Journal of Child Psychology and Psychiatry, 38, 581-586. http://onlinelibrary.wiley.com/doi/10.1111/j.1469-7610.1997.tb01545.x/pdf

Hagaman, J., Trout, A., DeSalvo, C., Gehringer, R., \& Epstein, M. (2010). The academic and functional academic skills of youth who are at risk for language impairment in residential care. Language, Speech, and Hearing Services in Schools, 41, 14-22. http://dx.doi.org/10.1044/0161-1461(2009/08-0089)

Ketelaars, M. P., Cuperus, J., Jansonius, K., \& Verhoeven, L. (2010). Pragmatic language impairment and associated behavioral problems. International Journal of Language \& Communication Disorders. 45, 204-214. http://dx.doi.org/10.3109/13682820902863090

Leonard, L. (2008). Children with specific language impairment. Cambridge, MA: MIT Press.

Maratsos, M. (2000). More over regularizations after all: new data and discussion on Marcus, Pinker, Ullman, Hollander, Rosen \& Hu. Journal of Child Language, 27, 183-212.

Parish, P. (1963). Amelia Bedelia. New York: Harper \& Row.

Redmond, S. M. (2002). The use of rating scales with children who have language impairments. American Journal of Speech-Language Pathology, 11, 124-138. http://dx.doi.org/10.1044/1058-0360(2002/013)

Rice, M.L., Smolik, F., Perpich, D., Thompson, T., Rytting, N., \& Blossom, M. (2010). Mean length of utterance levels in 6-month intervals for children 3 to 9 Years with and without language impairments. Journal of Speech, Language, and Hearing Research, 53, 333-349. http://dx.doi.org/10.1044/1092-4388(2009/08-0183)

Ripley, K., \& Yuill, N. (2005). Patterns of language impairment and behavior in boys excluded from school. British Journal of Educational Psychology, 75, 37-50.

Snowling, M. J., Adams, J. W., Bishop, D. M. V., \& Stothard, S. E. (2001) Educational attainments of school leavers with a preschool history of speech-language impairments. International Journal of Language \& Communication Disorders, 36, 173-183. http://dx.doi.org/10.1080/13682820120976

Vaughn, S., Linan-Thompson, S., \& Hickman, P. (2003). Response to instruction as a means of identifying students with reading/learning disabilities. Exceptional Children, 69, 391-409.

\section{$(\mathrm{cc}) \mathrm{BY}$}

This work is licensed under a Creative Commons Attribution 3.0 License. 